\title{
DEVICE FOR IN VITRO WEAR ANALYSIS OF BIOMATERIALS IN THE HINGED PROSTHESIS CONFIGURATION
}

\author{
UDC 620:617.3
}

\author{
José N. Athayde ${ }^{1}$, Beatriz L. Fernandes ${ }^{1}$, Carlos J. de M. Siqueira ${ }^{2}$, \\ Percy Nohama ${ }^{1}$, Carlos R. Fernandes ${ }^{1}$ \\ ${ }^{1}$ Pontifical Catholic University of Paraná, Health Technology, Curitiba, Brazil \\ ${ }^{2}$ Federal University of Paraná, Department of Mechanical Engineering, Curitiba, Brazil
}

\begin{abstract}
We have developed a device that, coupled to the tribometer, allows movement simulation of the hinged type knee prosthesis. Two tests were performed using the samples designed and one test without the device using a pin-on-flat configuration. For the first and the third tests, the metallic samples were used as machined while for the second one they were electrolytically polished. The test parameters were running length of 0.663 rad and compression load of $22.35 \mathrm{~N}$. The Hertzian contact stress of $15.93 \mathrm{MPa}$ obtained between the samples designed is close to that for the real prosthesis. The measured volumetric wear revealed the influence of roughness of the counterpart surface on the wear behavior. The device has allowed its coupling to the tribometer without any interference on its functioning thus making a contribution to the scientific investigations related to wear behavior of a couple of different biomaterials.
\end{abstract}

Key Words: Wear Testing, Sliding Wear, Three-body Abrasion, Joint Prosthesis, Hinged Knee Prosthesis

\section{INTRODUCTION}

A simply hinged prosthesis is one of the configurations used in the knee prosthesis although it cannot provide complex movements of the knee joint. Total Knee Arthroplasty (TKA) is a surgical procedure involving the insertion of an artificial joint that replaces the natural one degenerated by osteoarthritis [1], trauma or tumor.

Received June 23, 2017 / Accepted July 11, 2018

Corresponding author: Beatriz Luci Fernandes

Graduate Program on Health Technology, Pontifical Catholic University of Paraná - PUCPR, Rua Imaculada Conceição, 1155, 80215-901 Curitiba PR, Brazil

E-mail: beatriz.fernandes@pucpr.br 
The total knee prostheses are classified depending on the extension of the tibia and femur resection. The conventional prosthesis is chosen when the resection is limited to the borders of the joint while the unconventional one is chosen when a part of the tibia and the femur has to be removed $[2,3]$.

A variety of studies reports on the tribological behavior of a couple of biomaterials used in the conventional knee prosthesis. However, very few of them are found to be focused on unconventional knee prostheses (UNCKP). Despite the diversity of models of the last ones and although their use is commonly intended for oncological patients, the new diagnostic techniques and treatments have been raising life expectations of those individuals [4]. Therefore, the development of a better design for unconventional prosthesis and its tribological characterization is worth discussion.

Like conventional prostheses, the unconventional ones are subjected to septic loosening due to infection and aseptic loosening due to excessive wear of the biomaterials in the sliding contact. The aseptic loosening is the main problem that leads to the prosthesis revision, affecting patients from 10 to 29 years after the replacement surgery $[2,5,6]$. In this case, the wear debris generated and released from the biomaterials in the joint prosthesis accumulates in the adjacent tissue, and depending on the size and quantity, it can destroy it $[7,8]$. The amount and morphology of the released debris are related mainly to the biomaterials properties and congruency between the surfaces in contact that leads to punctual load conditions [9]. Therefore, the contact pressure between the prosthesis parts directly influences wear of the biomaterials and must be evaluated in order to assist to the proper design of the implants [10].

The tests performed in the tribometer can provide initial data about the tribological behavior of the biomaterials couple involved in prosthesis production; however, without the simulation of the real loads, the range of movements and superficial contact area it is not possible to make conclusions about their behavior in vivo.

Although there are gait simulators for validation of materials and designs of knee prosthesis, the tests are expensive and time-consuming being used mainly on the final products for regulatory reasons.

Based on the context exposed herein, in the present work we have designed, produced and evaluated a device that, linked to a linear tribometer, can perform a wear test in biomaterial couple simulating the loads and the boundary conditions that occur in vivo in an unconventional total knee prosthesis hinged type.

\section{MATERIALS AND METHODS}

The device is designed to fit a Linear Tribometer $\mathrm{CSM}^{\circledR}$ that allows a maximum load of $46 \mathrm{~N}$, the linear sliding amplitude of $20 \mathrm{~mm}$ and a maximum speed of $31 \mathrm{~cm} / \mathrm{s}$. Apart from the reciprocal linear motion module, none of the original mechanisms or electronic sensors of the tribometer was modified or taken away to adapt the device. Therefore, the device uses the structure, the rotation mechanism, the sensors system for load and speed and the headstock adjustment of the tribometer. The controlled parameters are speed, frequency, and rotation.

The design of the samples manufactured for the tests in the present study is based on the most frequent design of the total unconventional knee prosthesis available on the market. It has one degree of freedom allowing only flexion and extension. Since the knee prosthesis 
causes an oscillatory movement, in order to reproduce it using the tribometer, it was necessary to convert the tribometer rotational mechanism, exposed when the reciprocal linear motion module is detached, into oscillatory one. This was done through a tilting coupling assembled perpendicularly to the tribometer eccentric shaft, which was so conceived as to support a small stainless steel vat where the samples could be tested immersed in lubricant fluid. The tribometer rotational movement was converted into tilting one with a maximum angular amplitude of $\pm 9,49^{\circ}$ (right and left), limited by the tribometer design.

The mechanical support of $12.0 \mathrm{~mm}^{2}$ section bar was built with AISI 304 stainless steel that suites the requirements of corrosion and mechanical resistances for this application.

Seeing that the UNCKP functions as a hinge [11], the samples for the wear test using the device and the tribometer are designed to simulate the Hertzian contact that happens in the UNCKP in vivo. A couple of samples manufactured in the usual biomaterials for a joint prosthesis, Ti6Al4V alloy and Ultra High Molecular Weight Polyethylene (UHMWPE), have the dimensions presented in Fig. 1, fixed through the designed parts. In this way, the contact between the surfaces of the titanium alloy and the polyethylene samples is made by a curvature radius of $3.0 \mathrm{~mm}$, corresponding to twice the maximum angular amplitude of $\pm 9,49^{\circ}$ or $18,98^{\circ}$. This value is the total course conducted by a contact point between the two samples during the test.
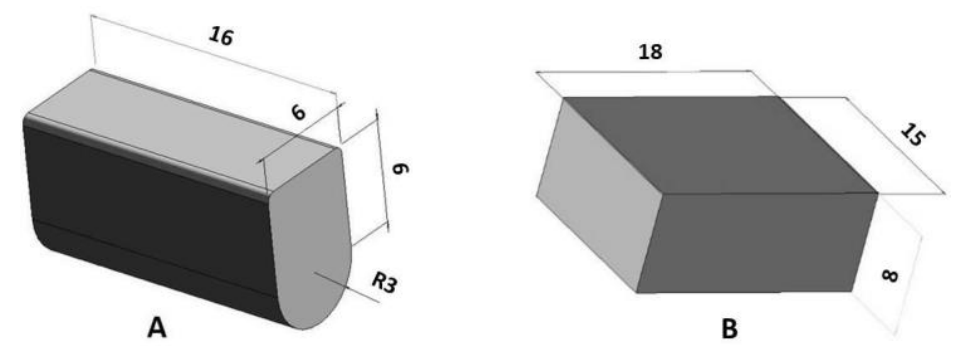

Fig. 1 Samples designed for use in the device: (A) metallic sample in Ti6Al4V alloy with dimensions in $\mathrm{mm}$ and (B) polymeric sample in UHMWPE with dimensions in $\mathrm{mm}$

To perform the device assessment, a course of $0.663 \mathrm{rad}$, resulting in a distance of $1.98 \mathrm{~mm}$, is considered.

The configuration of the tribometer $\mathrm{CSM}^{\circledR}$ with the adapted device is obtained through the software Tribox ${ }^{\circledR}$ inserting the parameters: load, cycle time corresponding to $1 / 2$ of the amplitude of the eccentric bearing, properties of material samples, and environment temperature and humidity.

The free software HertzWinTM with the parameters presented in Table 1 is used to simulate the Hertzian contact stress that occurs in the UNCKP in order to compare to the proposed test configuration. The contact between the materials is considered cylindricalcylindrical for UNCKP (hinge type) $[12,13]$ and cylindrical-flat for the designed sample couple shown in Fig. 2. A compression load of $3 \mathrm{kN}$ is considered for the UNCKP simulation supposing a subject with $70 \mathrm{~kg}$ weight multiplied by a factor of 4.2 [14] while the load of $25.35 \mathrm{~N}$ is applied to the designed samples in the simulation, which is limited by the tribometer configuration. 

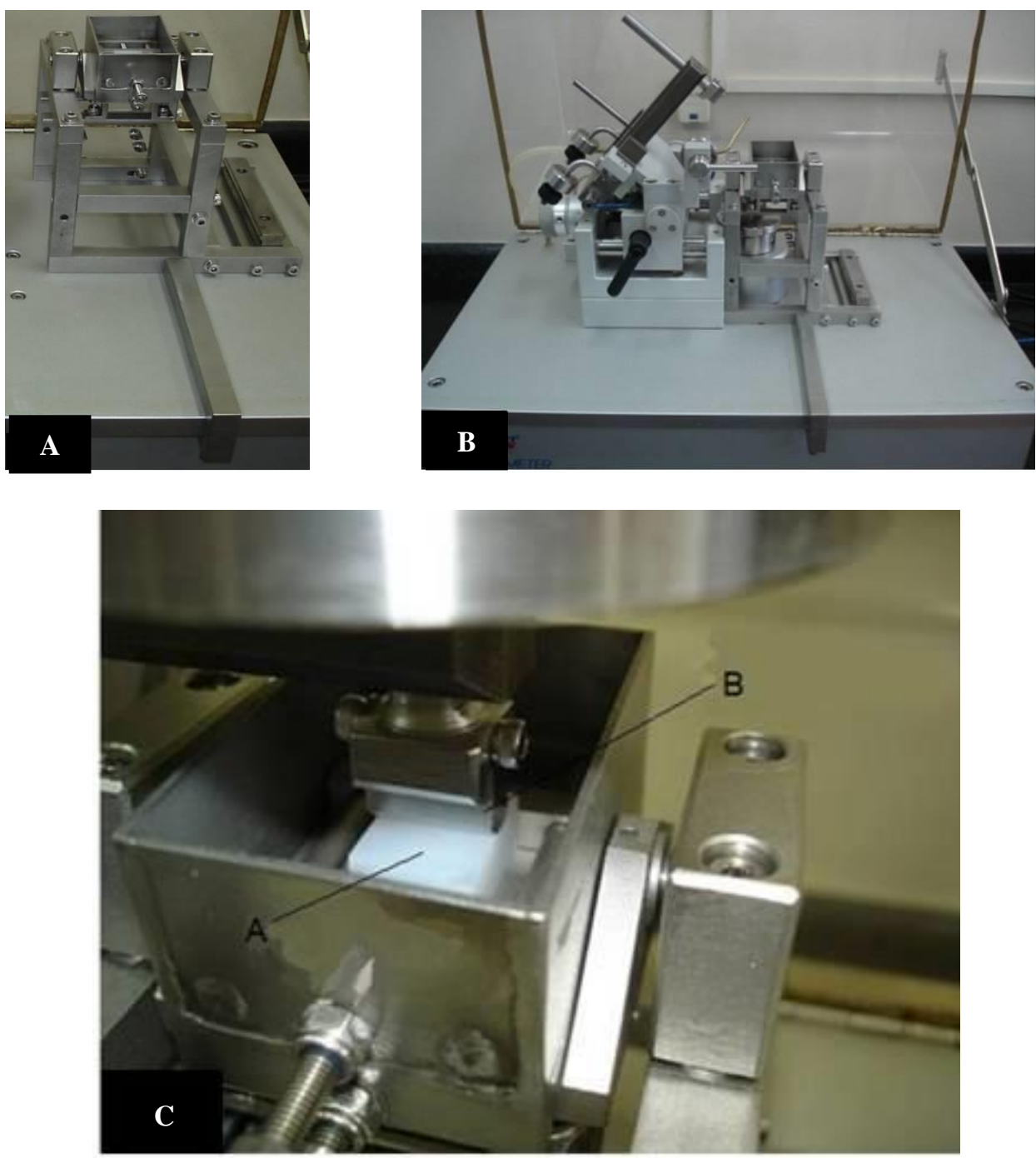

Fig. 2 (A) The device designed alone; (B) the device adapted to the tribometer; and (C) detail of the designed samples (A - UHMWPE and B - Ti6Al4V) and the stainless steel vat

The results from the software HertzWinTM show 15.93 MPa of the Hertzian contact stress between the samples designed against $15.14 \mathrm{MPa}$ for the UNCKP simulation, suggesting that the samples designed and the test load applied can simulate the stress in vivo. With these results, the tests with the device were performed. 
Table 1 Parameters used to simulate the Hertzian contact stress using the software HertzWinTM, for the couple UHMWPE-Ti6Al4V applied in real UNCKP and in samples designed to use on the tribometer $[12,15,16]$

\begin{tabular}{lcccc}
\hline \multirow{2}{*}{ Parameters } & \multicolumn{2}{c}{ UHMWPE } & \multicolumn{2}{c}{ Ti6Al4V } \\
\cline { 2 - 5 } & UNCKP & $\begin{array}{c}\text { Samples } \\
\text { designed }\end{array}$ & UNCKP & $\begin{array}{c}\text { Samples } \\
\text { designed }\end{array}$ \\
\hline Young Modulus (GPa) & 1.2 & 1.2 & 110 & 110 \\
Poisson coefficient & 0.4 & 0.4 & 0.34 & 0.34 \\
Contact geometry & Cylindrical & Flat & Cylindrical & Cylindrical \\
Contact radius (mm) & -6.8 & $\infty$ & 6.5 & 3.0 \\
Contact length (mm) & 40 & 15 & 40 & 15 \\
Load $(\mathrm{N})$ & 3000 & 25.35 & 3000 & 25.35 \\
\hline
\end{tabular}

The Ti6Al4V alloy and UHMWPE samples are machined, cleaned and sterilized with Ethylene oxide (EtO) before the testing procedure. With the purpose of the device assessing, three tests are performed according to the parameters presented in Table 2: two tests with the samples designed and one without the device using a pin ( $15 \mathrm{~mm}$ length $\mathrm{x} 6$ $\mathrm{mm}$ diameter) and a flat with the same dimensions of the previous tests.

Table 2 Parameters used in tests to evaluate the device

\begin{tabular}{lccc}
\hline Parameters & Test 1 & Test 2 & Test 3* \\
\hline Contact surfaces & Cylindrical Ti6Al4V/ & Cylindrical Ti6Al4V/ & Ti6Al4V pin/ \\
& flat UHMWPE & flat UHMWPE & flat UHMWPE \\
Constant load & $25.35 \mathrm{~N}$ & $25.35 \mathrm{~N}$ & $25.35 \mathrm{~N}$ \\
Number of cycles & 500.000 & 500.000 & 500.000 \\
Frequency & $2.0 \mathrm{~Hz}$ & $2.0 \mathrm{~Hz}$ & $2.0 \mathrm{~Hz}$ \\
Lubrication & No lubricant & No lubricant & No lubricant \\
Temperature & $21.5 \pm 1.5^{\circ} \mathrm{C}$ & $22.0 \pm 1.5^{\circ} \mathrm{C}$ & $21.5 \pm 1.5^{\circ} \mathrm{C}$ \\
Relative humidity & $60.0 \pm 10 \%$ & $60.0 \pm 10 \%$ & $60.0 \pm 10 \%$ \\
\hline
\end{tabular}

The third test is intended to evaluate the importance of the designed samples over the tribometer performance and the influence of the Hertzian contact stress over the wear. For the first test, a metallic sample is used as machined without any subsequent finishing as well as the pin for the third test. On the contrary, the metallic sample for the second test receives electrolytic polishing before the test. For test 3, to match the sliding distance between the designed samples and the common ones, the tribometer amplitude is set to $1 / 2$.

The Hertzian contact stress in each test from Table 2 is determined by HertzWinTM using spherical (3,0 mm contact radius) - flat (infinite contact radius): $15.93 \mathrm{MPa}$ for Test 1, 15.93 MPa for Test 2, and 102.93 MPa for Test 3.

Due to a low wear rate of the UHMWPE, the gravimetric wear determination is strongly affected by intrinsic uncertainty of the measurement [17]. The alternative is to determine the area of the grooves formed in the UHMWPE sample during the test due to adhesive wear mechanisms $[17,18]$ using a contact stylus profilometer Veeco DEKTAK150. The volumetric wear is determined through the area integration (sum of the area of several rectangles that fill the area formed by the curve). 


\section{RESULTS}

One example of the 2D profile provided by the contact stylus profilometer Veeco DEKTAK-150 is presented in Fig. 3.

The volumetric wear with the standard deviations for the areas used to calculate them is presented in Table 3. It was considered that the Student's T-Test distribution with n-1 degree of freedom for the samples and four measurements were made for each sample.

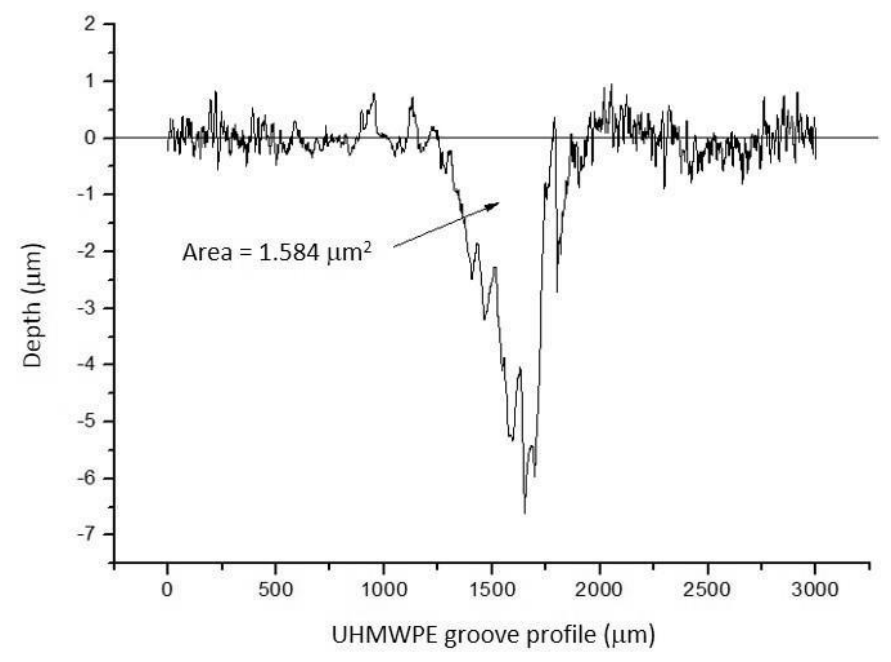

Fig. 3 One of the UHMWPE groove profiles provided by the profilometer Veeco DEKTAK-150

Table 3 Volumetric wear for each test and the standard deviation of the mean area value

\begin{tabular}{ccc}
\hline Test & $\begin{array}{c}\text { Volumetric wear } \\
\left(\mathrm{mm}^{3}\right)\end{array}$ & $\begin{array}{c}\text { Area standard deviation } \\
\left(\mathrm{mm}^{2}\right)\end{array}$ \\
\hline 1 & $2.93 \times 10^{-2}$ & $\pm 9.04 \times 10^{-4}$ \\
2 & $3.47 \times 10^{-2}$ & $\pm 5.06 \times 10^{-4}$ \\
3 & $8.41 \times 10^{-2}$ & $\pm 2.70 \times 10^{-4}$ \\
\hline
\end{tabular}

The surface roughness of the designed samples for the test 1 is $0.628 \mu \mathrm{m}$ for Ti6Al4V alloy (as machined) and $0.265 \mu \mathrm{m}$ for UHMWPE. For the test 2, roughness is $0.277 \mu \mathrm{m}$ for the Ti6Al4V sample (electrolytic polishing) and $0.285 \mu \mathrm{m}$ for the UHMWPE sample. Finally, for the test 3 , roughness is $0.628 \mu \mathrm{m}$ for the Ti6Al4V alloy pin (as machined) and $0.299 \mu \mathrm{m}$ for the flat UHMWPE.

\section{DISCUSSION}

As one can see from Table 3, the wear for the second test $\left(3.47 \times 10^{-2} \mathrm{~mm}^{3}\right)$ is higher than for the first one $\left(2.93 \times 10^{-2} \mathrm{~mm}^{3}\right)$. In the test configuration, the only difference is the surface roughness of the metallic samples. The reason for this is that the difference 
between the roughness of the UHMWPE samples is negligible because the three samples are used as machined (no surface treatment). This behavior is consistent considering that the UHMWPE wear is extremely sensitive to the roughness of the counterpart surface [18] that should be as smooth as possible [19].

The UHMWPE part is abraded when sliding against a harder surface releasing debris, and both surfaces may be abraded by harder third bodies [17, 20]. However, in nolubrication conditions with little hard third bodies as in the tests performed herein, part of the UHMWPE is transferred to the Ti6Al4V counter face forming a lubricating film [18] suggesting that the differences between the initial surface roughness may not be as significant in the wear analysis as in the test conditions.

The tribometer did not suffer any interference in functioning when coupled to the developed device. Until now, there is no report about devices that simulate unconventional knee prosthesis. Therefore, the device presented in this work brings a significant contribution to the scientific research related not only to this kind of prosthesis but also to the tribological behavior of counter faces of different biomaterials.

The device also allows performing tests with samples immersed in lubricant, including bovine serum, which allows comparison with the results obtained from wear tests of the conventional knee prosthesis performed on gait simulators.

The angle of $37.96^{\circ}$ that is equivalent to the total sliding trajectory of the sample (back and forth) is the maximum value allowed by the eccentric bearing of the tribometer. Although the flexion angle in in vivo knee prosthesis is higher [21], it does not affect the wear performance since, for the hinged prosthesis, the congruence between the surfaces is the crucial parameter. The sliding distance can be compensated by increasing the number of cycles.

The higher volumetric wear from the conventional pin-on-flat test (test 3) confirms the influence of the geometry of samples in wear behavior. It is clear that the smaller contact area and consequently a higher Hertzian stress is responsible for the poorer performance in wear resistance compared to the designed samples. The higher stress provokes a higher deformation of the UHMWPE part resulting in a higher wear rate, initially by adhesion wear and, after the adhered debris is released, by abrasive wear. Both wear mechanisms are commonly identified in the total knee prosthesis [22].

Through the HertzWinTM free software, the Hertzian contact stress value of $15.93 \mathrm{MPa}$ obtained between the designed samples is very close to the value of $15.14 \mathrm{MPa}$ obtained in the simulation of real unconventional knee prosthesis. This result demonstrates that the sample designs are adequate to simulate the contact that occurs in the unconventional knee prosthesis in vivo.

\section{CONCLUSION}

The conceived device allows its adaptation to a conventional linear tribometer without any interference in its functioning. This characteristic proves the functionality of the device in assessing wear resistance between the couples of biomaterials intended to be applied to sliding movements.

The samples geometries provide the movement simulation of the unconventional total knee prosthesis, respecting its degree of freedom and Hertzian stress as well as allowing realistic performance evaluation of the biomaterials couple before expensive tests in gait simulators. 
A profilometer is convenient to obtain volumetric wear, especially when the debris volume or its isolation does not reach an accurate mass measurement.

\section{REFERENCES}

1. Dieterich, J.D., Fields, A.C., Moucha, C.S., 2014, Short term outcomes of revision total knee arthroplasty, Journal of Arthroplasty, 29(11), pp. 2163-2166.

2. Robertsson, O., Lewold, S., Knutson, K., Lidgren, L., 2000, The Swedish knee arthroplasty project, Acta Orthopaedia Scandinavica, 71(1), pp. 7-18.

3. Tsal, L.Y., Garcia, R.J., Petrilli, A.S., Korukian, M., Viola, D.C.M., Petrilli. M. de T., Godoy, F.A.C., 2007, Protocolo fisioterapêutico em pacientes submetidos à endoprótese não convencional de joelho por osteossarcoma: estudo prospectivo, Revista Brasileira de Ortopedia, 42(3), pp. 64-70.

4. Mantyh, P., 2013, Bone cancer pain: Causes, consequences, and therapeutic opportunities, Pain, 154, pp. S54-S62.

5. Atwood, S.A., Currier, J.H., Mayor, M.B., Collier, J.P., Van Citters, D.W., Kennedy, F.E., 2008, Clinical wear measurement on low contact stress rotating platform knee bearings, Journal of Arthroplasty, 23(3), pp. 431-440.

6. Bertin, K.C., 2007, Tibial Component Fixation in Total Knee Arthroplasty, Journal of Arthroplasty, 22(5), pp. 670-678.

7. Abu-Amer, Y., Darwech, I., Clohisy, J.C., 2007, Aseptic loosening of total joint replacements: mechanisms underlying osteolysis and potential therapies, Arthritis Research \& Therapy, 9(1), pp. 1-7.

8. Bahraminasab, M., Sahari, B.B., Edwards, K.L., Farahmand, F., Arumugam, M., 2013, Aseptic loosening of femoral components - Materials engineering and design considerations, Materials and Design, 44, pp. 155-163.

9. Au, A.G., Raso, J., Liggins, A.B., Amirfazli, A., 2007, Contribution of loading conditions and material properties to stress shielding near the tibial component of total knee replacements, Journal of Biomechanics, 40 , pp. 1410-1416.

10. O'Brien, S.T., Luo, Y., Brandt. J-M., 2015, In-vitro and in-silico investigations on the influence of contact pressure on cross-linked polyethylene wear in total knee replacements, Wear, 332-333, pp. 687-693.

11. Grimer, R.J., Carter, S.R., Tillman, R.M., Sneath, R.S., Walker, P.S., Unwin, P.S., Shewell, P.C., 1999, Endoprosthetic replacement of the proximal tibia, Journal of Bone \& Joint Surgery, 81-B(3), pp. 488-494.

12. Manning, D.W., Chiang, P.P., Freiberg, A.A., 2005, Hinge Implants - Revision total knee arthroplasty, 1st ed. New York, Springer, pp. 219-222.

13. Fabroni, R.H., Steverlynck, A.M., Aguilera, A.L., Zeballos, J.I., 1994, Endoprótesis no convencionales Fabroni no cementadas, Revista de la Asociación Argentina de Ortopedia y Traumatología, 59(1), pp. 66-73.

14. Wehner, T., Claes, L., Simon, U., 2009, Internal loads in the human tibia during gait, Clinical Biomechanics, 24, pp. 299-302.

15. Tardy, N., Chambat, P., Murphy, C.G., Fayard, J.M., 2014, Bilateral custom-fit total knee arthroplasty in a patient with poliomyelitis, Orthopedics, 37(9), pp. e839-e843.

16. Long, M., Rack, H.J., 1998, Titanium alloys in total joint replacement - a materials science perspective, Biomaterials, 19, pp. 1621-1639.

17. González-Mora, V.A., Hoffmann, M., Stroosnijder, R., Gil, F.J., 2011, The role of hardness and roughness on the wear of different CoCrMo counterfaces on UHMWPE for artificial joints, Journal of Biomedical Science and Engineering, 4, pp. 651-656.

18. Ruggiero, A., D'Amato, R., Gómez, E., Merola, M., 2016, Experimental comparison on tribological pairs UHMWPE/TIAL6V4 alloy, UHMWPE/AISI316L austenitic stainless and UHMWPE/AL $L_{2} \mathrm{O}_{3}$ ceramic, under dry and lubricated conditions, Tribology International, 96, pp. 349-360.

19. Al-Samarai, R.A., Haftirman, Ahmad, K.R., Al-Douri, Y., 2012, Evaluate the effects of various surface roughness on the tribological characteristics under dry and lubricated conditions for Al-Si alloy, Journal of Surface Engineered Materials and Advanced Technology, 2, pp.167-173.

20. Poggie, R.A., Mishra, A.K., Davidson, J.A., 1994, Three-body abrasive wear behaviour of orthopaedic implant bearing surfaces from titanium debris, Journal of Materials Science: Materials in Medicine, 5, pp. 387-392.

21. Mundermann, A., Dyrby, C.O., D’Lima, D.D., Colwell, C.W., Andriacchi, T.P., 2008, In vivo knee loading characteristics during activities of daily living as measured by an instrumented total knee replacement, Journal of Orthopaedic Research, 26(9), pp. 1167-1172.

22. Gul, R.M., McGarry, F.J., Bragdon, C.R., Muratoglu, O.K., Harris, W.H., 2003, Effect of consolidation on adhesive and abrasive wear of ultra high molecular weight polyethylene, Biomaterials, 24, pp. 3193-3199. 